\title{
Optimasi dan Validasi Metode Kromatografi Cair Kinerja Tinggi untuk Menetapkan Kadar Asam Klorogenat dalam Ekstrak Etanol Daun Yakon (Smallanthus sonchifolius (Poepp. \& Endl.) H. Robinson)
}

\section{Zuhelmi Aziz $^{a^{*}}$, Liliek Nurhidayatia ${ }^{a}$, Syamsudin Abdillaha ${ }^{a}$, Nancy Dewi Yuliana ${ }^{b}$, Partomuan Simanjuntak ${ }^{c}$}

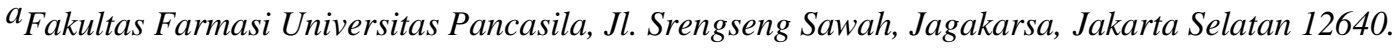 \\ ${ }^{b}$ Departemen of Food Science. Technology, Faculty of Agriculture Technology, IPB Dramaga Campus, \\ Bogor \\ ${ }^{c}$ Pusat Penelitian Bioteknologi, Lembaga Ilmu Pengetahuan Indonesia (LIPI), Jalan Raya Bogor Km 46, \\ Cibinong 16911. \\ * Corresponding author \\ E-mail: emi.ffup@yahoo.com
}

DOI: 10.20961/alchemy.16.1.28952.67-76

Received 28 March 2019, Accepted 12 February 2020, Published 01 March 2020

\begin{abstract}
ABSTRAK
Yakon merupakan tanaman yang dapat digunakan untuk pengobatan dan kebutuhan pangan. Salah satu kandungan zat berkhasiat dalam daun yakon adalah asam klorogenat. Asam klorogenat diketahui memiliki aktifitas sebagai antioksidan, antikanker dan antidiabetes. Penentuan kadar asam klorogenat dalam matriks yang kompleks diperlukan metode yang selektif dengan ketelitian dan ketepatan yang baik. Pada penelitian ini dilakukan optimasi dan validasi metode kromatografi cair kinerja tinggi (KCKT) fase balik untuk penetapan kadar asam klorogenat. Ekstrak dibuat secara ultrasonikasi menggunakan pelarut etanol 95\%. Kondisi optimum diperoleh menggunakan fase gerak asam format $0,1 \%$ dalam asetonitril-asam format $0,1 \%$ dalam air (gradien); fase diam oktadesilsilan $\left(\mathrm{C}_{18}\right)$ pada suhu $30^{\circ} \mathrm{C}$ dan detektor UV pada panjang gelombang $328 \mathrm{~nm}$. Metode KCKT ini memberikan hasil yang memiliki ketelitian yang tinggi dengan simpangan baku relatif 0,79\% dan ketepatan yang baik dengan perolehan kembali 97,50\%. Kadar asam klorogenat yang diperoleh dalam ekstrak etanol $95 \%$ daun yakon sebesar $1,02 \%$.
\end{abstract}

Kata kunci : asam klorogenat, kromatografi cair kinerja tinggi, optimasi, Smallanthus sonchifolius

\section{ABSTRACT}

Optimization and Validation of High Performance Liquid Chromatography Methods for Determination of Chlorogenic Acid Levels in Ethanol Extracts of Yakon Leaves (Smallanthus sonchifolius (Poepp. \& Endl.) H. Robinson). Yacon is a plant that can be used for medication and food needs. One of the bioactive compounds of yacon leaves is chlorogenic acid. Chlorogenic acid has various biological activities, such as antioxidant, anticancer and antidiabetic activities. Determination of chlorogenic acid in complex matrices required a methods with a good precision and accuracy. In this study, the optimization and validation of reverse phase high performance liquid chromatography (HPLC) method for chlorogenic acid 
determination were performed. The extract was prepared by ultrasonication in $95 \%$ ethanol.The optimized condition for HPLC were obtained by using mobile phase $0.1 \%$ formic acid in acetonitrile $-0.1 \%$ formic acid in water with gradient elution, stationary phase octadesylsilane $\left(\mathrm{C}_{18}\right)$ at $30^{\circ} \mathrm{C}$ and $\mathrm{UV}$ detector at of $328 \mathrm{~nm}$. The result showed that HPLC method had high precicion with relative standard deviation of $0.79 \%$ and high accuracy with recovery of $97.50 \%$. The chlorogenic acid in the ethanol $95 \%$ extract of yacon leaves was $1,02 \%$.

Keywords: chlorogenic acid, high performance liquid chromatography, optimization, Smallanthussonchifolius.

\section{PENDAHULUAN}

Yakon [Smallanthus sonchifolius (Poepp.\& Endl.) H. Robinson] dibudidaya di daerah Bandung dan Yogyakarta. Bagian yang sering digunakan saat ini untuk dikembangkan sebagai obat tradisional adalah daunnya. Di kalangan masyarakat daun yakon dikenal dengan nama daun insulin karena memiliki khasiat sebagai antidiabetes (Grau, 1997; Baroni et al., 2008; de Andrade et al., 2014 dan Zeng et al., 2017). Daunnya mengandung senyawa - senyawa fenolat di antaranya ialah asam klorogenat. Asam klorogenat dapat menurunkan kadar glukosa dalam darah, memperbaiki kinerja dari kelenjar pankreas dan dapat memperbaiki intoleransi glukosa serta resistensi insulin (Baroni et al., 2008). Tanaman atau bagian tanaman yang mengandung asam klorogenat telah digunakan sebagai sediaan herbal dan memiliki potensi efek farmakologi seperti: antidiabetes, antiartritis, antidiare, antiinflamasi, antirematik, antitumor, antivirus, astringen, kardiotonis, karminatifa, antiseptik intestinal, purgatif, dan efek spasmolitik. Tanaman obat yang mengandung asam klorogenat juga digunakan untuk demam, hematemesis, hematuria, hemorroid, lumbago, neuralgia, tinnitus dan sakit gigi (Grau, 1997).

Salah satu kontrol kualitas dalam menjamin mutu ekstrak tanaman adalah kandungan zat berkhasiat. Penetapan kadar zat dalam matriks yang kompleks seperti dalam ekstrak daun yakon diperlukan metode yang selektif dengan ketelitian dan ketepatan yang memenuhi persyaratan untuk metode yang valid. Salah satu metode tersebut adalah kromatografi cair kinerja tinggi (KCKT). KCKT telah digunakan untuk identifikasi dan menetapkan kadar senyawa - senyawa aktif dalam suatu tanaman. Pada penelitian sebelumnya telah dilakukan penetapan kadar asam klorogenat dalam ekstrak etanol 70\% daun yakon menggunakan KCKT dengan detektor elektrokimia (HPLC-ECD) menggunakan elusi isokratik dan fase gerak $25 \mathrm{mM}$ mono kalium fosfat - asetonitril (80:20). Hasil penelitian tersebut menunjukkan puncak asam klorogenat muncul pada waktu retensi 16,02', rentang 
pengukuran $0,96-24,0 \mathrm{mg} / \mathrm{L}$ serta batas deteksi $0,96 \mathrm{mg} / \mathrm{L}$ dengan kadar yang didapatkan sebesar $62 \% \mathrm{~b} / \mathrm{b}$.

Menurut Baroni et al. (2016), untuk memisahkan senyawa fenolik yang ada di dalam ekstrak etanol-air daun yakon digunakan metode KCKT fase balik dengan kondisi kolom C18, detektor UV-Vis dan fase gerak metanol - asam asetat 4\% (3:7). Zeng et al. (2017) melakukan pemisahan senyawa fenolik daun yakon menggunakan metode KCKT dengan kondisi kolom $\mathrm{C} 18$, detektor diode array (DAD), fase gerak menggunakan asam formiat $1 \%$ (A) dan metanol (B), dan menggunakan elusi gradien dengan komposisi elusi: menit $0-40$, $25 \%-40 \%$ (B); menit $40-55,40 \%-75 \%$ (B); dan menit $55-65,75 \%-25 \%$ (B). Kadar asam klorogenat dalam campuran yang mengandung asam vanilat, asam kafeat dan asam rosmarinat, menggunakan dua panjang gelombang, pada penelitian ini digunakan satu panjang gelombang yaitu $328 \mathrm{~nm}$ dengan detektor UV.

Zeng et al. (2017) melaporkan penetapan kadar senyawa - senyawa fenolik menggunakan metode KCKT dengan detektor ultraviolet-visible (HPLC UV-Vis) yang diukur pada panjang gelombang $280 \mathrm{~nm}$ dengan laju alir $1,0 \mathrm{~mL} /$ menit metode fase balik dengan elusi gradien menggunakan tiga macam fase gerak yaitu asetonitril 5\% (A), 0,5\% asam formiat dalam 5\% asetontril (B), dan asetonitril 100\% (C) dengan komposisi sebagai berikut: menit $0-15$ fase gerak A:B:C $=88 \%: 10 \%: 2 \%$; menit $15-18$ fase gerak A:B:C $=80 \%: 10 \%: 10 \%$; menit $18-30$ fase gerak $\mathrm{A}: \mathrm{B}: \mathrm{C}=70 \%: 10 \%: 20 \%$; menit $30-40$ fase gerak $\mathrm{A}: \mathrm{B}: \mathrm{C}=65 \%: 10 \%: 25 \%$; dan menit $40-42$ fase gerak $\mathrm{A}: \mathrm{B}: \mathrm{C}=0 \%: 0 \%: 100 \%$ (Baroni et al., 2016). Pada penelitian lain, telah dilakukan pemisahan asam klorogenat dalam ekstrak biji kopi hijau menggunakan metode KCKT fase balik dengan kondisi kolom C18, detektor UV-Vis dan fase gerak asam format $0,1 \%$ dalam asetonitril - asam format $0,1 \%$ dalam air (Ayelign and Sabally, 2013).

Penetapan kadar asam klorogenat dalam ekstrak etanol 95\% daun yakon dari Jawa Barat sejauh kajian pustaka yang dilakukan belum ditemukan. Oleh karena itu perlu dilakukan optimasi dan validasi metode KCKT untuk menetapkan kadar asam klorogenat dalam ekstrak etanol daun Yakon (Smallanthus sonchifolius (Poep.\& Endl.) H. robinson). 


\section{METODE PENELITIAN}

\section{Bahan dan Peralatan Penelitian}

Simplisia daun yakon (Smallanthus sonchifolius (Poepp. \& Endl.) H. robinson) diperoleh dari BALITRO, Bogor, Jawa Barat. Baku pembanding asam klorogenat diperoleh dari Sigma Aldrich (St. Louis, USA). Timbangan analitik Sartorius TE214S (Sartorius, Göttingen, Germany), ultrasonic LC 30 H Elma (Elma Schmidbauer Gmbh, GottliebDaimLer Straß 17 78224, Singen, Germany), dan KCKT LC-20 AD (Shimadzu, Kyoto, Japan).

\section{Pembuatan Ekstrak Kering}

Sebanyak 100 g simplisia kering daun yakon (Smallanthus sonchifolius (Poepp.\& Endl.) H. Robinson) diekstraksi dengan ultrasonikasi selama 30 menit menggunakan total pelarut etanol 95\% sebanyak $1000 \mathrm{~mL}$. Ekstraksi dilakukan sebanyak 3 kali dengan perincian volume pelarut: untuk ekstraksi pertama digunakan $500 \mathrm{~mL}$ etanol 95\%, ekstrak ditampung lalu residu dari ekstraksi pertama diekstraksi kembali menggunakan $250 \mathrm{~mL}$ etanol $95 \%$, dan ekstrak dikumpulkan dengan hasil ekstraksi pertama. Selanjutnya residu dari ekstraksi kedua diekstraksi lagi menggunakan $250 \mathrm{~mL}$ etanol 95\%. Ekstrak dikumpulkan, dipekatkan dengan vacuum rotary evaporator sampai diperoleh ekstrak yang kental. Ekstrak kental kemudian dikeringkan menggunakan freeze dryer.

\section{Penentuan Kondisi Optimum}

Penentuan panjang gelombang serapan maksimum untuk detektor dilakukan dengan membuat spektrum serapan larutan baku pembanding asam klorogenat $10 \mu \mathrm{g} / \mathrm{mL}$ dalam metanol pada panjang gelombang 200-400 nm menggunakan spektrofotometer Shimadzu UV 1700. Pada penelitian ini fase diam KCKT yang digunakan adalah XBridge C18 (4,6 x $150 \mathrm{~mm} ; 4,6 \mu \mathrm{m})$. Fase gerak yang dicoba adalah asetonitril- asam formiat $1 \%$ dalam metanol, asetonitril 5\% - metanol 0,5\% dalam asetonitril-asetonitril 100\% dan asam format $0,1 \%$ dalam asetonitril - asam format $0,1 \%$ dalam air secara elusi gradien dan asetonitril.

\section{Uji Kesesuaian Sistem}

Uji kesesuaian sistem dilakukan dengan menyuntikkan larutan baku pembanding 10 bpj, disaring dengan kertas saring $0,2 \mu \mathrm{m}$ dan disonikasi. Kondisi KCKT yang digunakan adalah fase diam XBridge $\mathrm{C} 18(4,6 \times 150 \mathrm{~mm}$; 4,6 $\mu \mathrm{m})$, suhu kolom $30^{\circ} \mathrm{C}$, fase gerak asam format $0,1 \%$ dalam asetonitril-asam format $0,1 \%$ dalam air, laju alir $0,8 \mathrm{~mL} / \mathrm{menit}$ dengan detektor sinar UV $328 \mathrm{~nm}$. 


\section{Uji Linearitas, Batas Deteksi dan Kuantitasi}

Uji linearitas dilakukan dengan membuat satu seri larutan yang dibuat dengan menambahkan sejumlah $1 \mathrm{~mL}$ larutan sampel dengan tujuh konsentrasi yang berbeda 0,$5 ; 1$; $2 ; 4 ; 8 ; 12 ; 16 \mu \mathrm{g} / \mathrm{mL}$ kedalam masing-masing labu takar $10 \mathrm{~mL}$, kemudian masing-masing ditambahkan metanol sampai garis tanda, disonikasi 3-4 menit diinjeksikan pada kondisi optimum. Dari kurva pada uji linearitas dapat ditentukan batas deteksi dan batas kuantitasi metode.

\section{Uji Presisi dan Akurasi}

Uji presisi dan akurasi dilakukan dengan menyuntikkan sejumLah $20 \mu \mathrm{L}$ larutan sampel yang telah ditambahkan larutan baku pembanding dengan tiga konsentrasi yang berbeda yaitu 4,8 , dan $12 \mu \mathrm{g} / \mathrm{mL}$ untuk menguji keakuratan dan ketelitian metode. Larutan sampel disaring dengan membrane filter 0,45 $\mu \mathrm{m}$ dan disonikasi selama 3-4 menit, kemudian diukur luas puncaknya pada kondisi KCKT optimum. Pengerjaan dilakukan 3 kali untuk masing - masing konsentrasi.

\section{HASIL DAN PEMBAHASAN}

Penetapan kondisi optimum KCKT untuk penetapan kadar asam klorogenat dilakukan menggunakan tiga kondisi yang berbeda yatu: asetonitril-asam formiat $1 \%$ dalam metanol, asetonitril 5\% -metanol 0,5\% dalam asetonitril-asetonitril 100\% dan asam format $0,1 \%$ dalam asetonitril-asam format $0,1 \%$ dalam air dengan elusi gradien, dengan detektor UV $328 \mathrm{~nm}$.

Kondisi pertama menghasilkan waktu retensi asam klorogenat baku dan ekstrak berturut-turut 1,644 dan 1,655 menit, tetapi kromatogram asam klorogenat memiliki nilai tailing (T) 3,295. Pada kondisi kedua, waktu retensi hampir sama dengan kondisi pertama tetapi luas puncak kecil, sedangkan pada kondisi ketiga waktu retensi asam klorogenat baku dan ekstrak berturut-turut 6,414 menit dan 6,349 menit dengan nilai T cukup baik berturutturut 1,32 dan 1,27. Oleh karena itu, dipilih kondisi ketiga sebagai kondisi optimum dengan fase gerak asam format $0,1 \%$ dalam air-asam format $0,1 \%$ dalam asetonitril dengan laju alir $0,8 \mathrm{~mL} / \mathrm{menit}$. Kromatogram pada kondisi ini dapat dilihat pada Gambar 1 .

\section{Hasil Uji Kesesuaian Sistem}

Puncak asam klorogenat muncul dengan waktu retensi 6,4 menit. Pada penyuntikan larutan baku pembanding $10 \mu \mathrm{g} / \mathrm{mL}$ dan dilakukan sebanyak 6 kali menghasilkan luas 
puncak dengan simpangan baku relatif (SBR) 2,09\% memenuhi persyaratan Farmakope Indonesia Edisi V, yaitu SBR tidak lebih dari 2,0\%. Dari hasil uji kesesuaian sistem dapat disimpulkan bahwa kondisi operasional untuk menganalisis asam klorogenat secara KCKT sudah membentuk suatu kesatuan sistem yang dapat memberikan hasil yang baik.

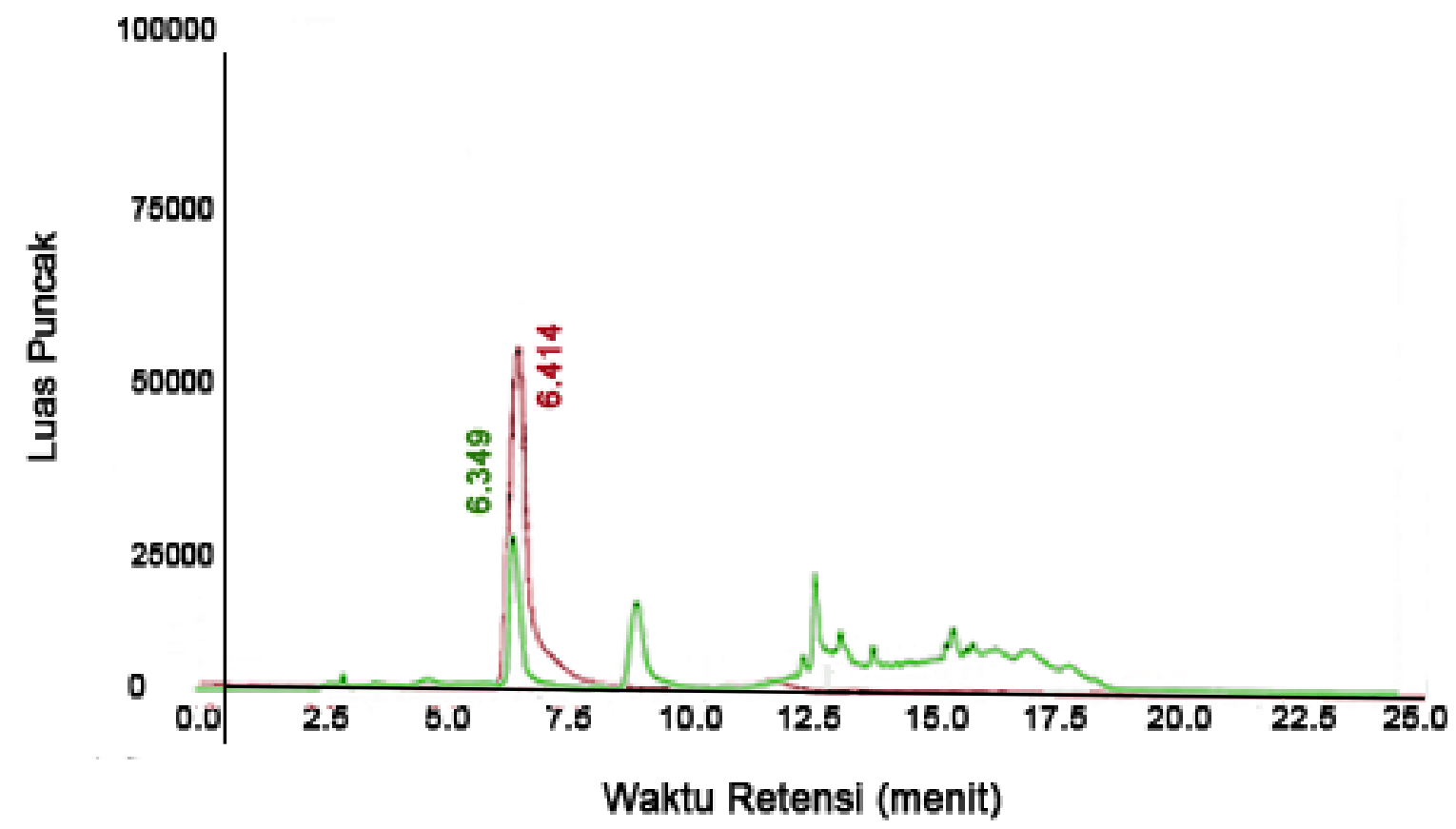

Gambar 1. (a) Kromatogram ekstrak etanol 95\% (hijau) dan (b) standar asam klorogenat (merah) dengan kondisi KCKT fase gerak asam format $0,1 \%$ dalam asetonitril - asam format $0,1 \%$ dalam air dengan laju alir $0,8 \mathrm{~mL} / \mathrm{menit}$

\section{Hasil Uji Linearitas, Batas Deteksi dan Batas Kuantitasi}

Uji linearitas dilakukan terhadap satu seri sampel dengan penambahan baku pembanding asam klorogenat menghasilkan persamaan garis regresi $\mathrm{y}=36897 \mathrm{x}+29164$ dengan nilai koefisien korelasi $\left(\mathrm{R}^{2}\right)$ 0,9694 pada rentang konsentrasi 0,5 sampai $16 \mu \mathrm{g} / \mathrm{mL}$ (Gambar 2). Nilai koefisen korelasi (R) yang mendekati nilai 1 menunjukkan bahwa tidak ada pengaruh matriks terhadap analit pada metode yang digunakan. Hasil uji linearitas dapat dilihat pada Gambar 2. Penetapan batas deteksi dan batas kuantitasi diambil dari hasil uji linearitas asam klorogenat dalam ekstrak etanol yang ditunjukkan Gambar 2. 


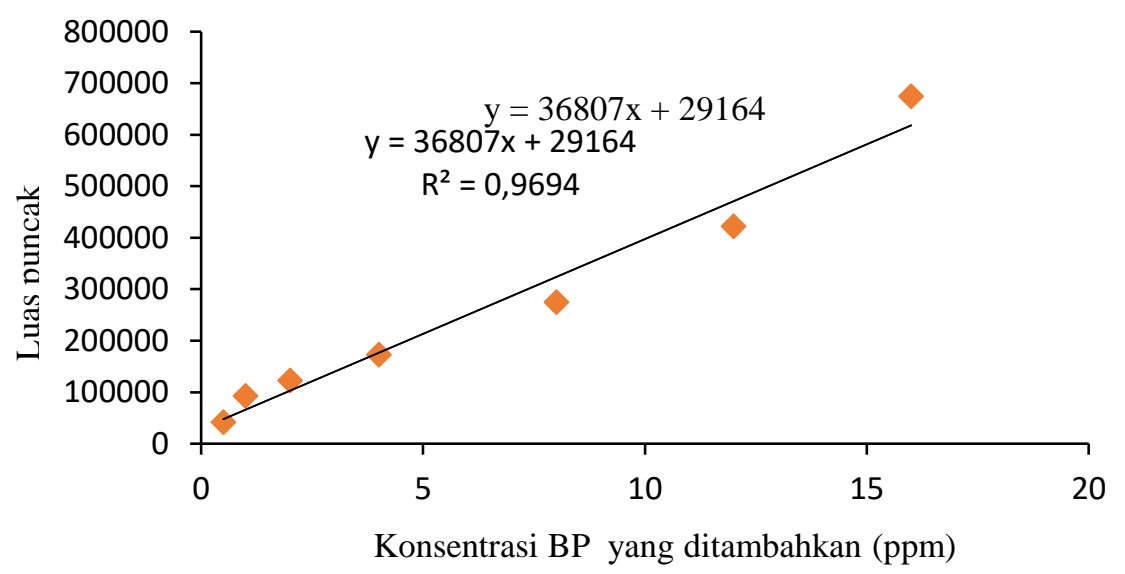

Gambar 2. Kurva standar hubungan antara konsentrasi asam klorogenat dengan luas puncak.

Hasil uji batas deteksi konsentrasi terendah asam klorogenat dalam sampel yang masih dapat dideteksi sebesar 3,32 $\mu \mathrm{g} / \mathrm{mL}$. Hasil uji batas kuantitasi memberikan informasi konsentrasi terendah asam klorogenat dalam sampel yang masih dapat ditetapkan kadarnya dengan akurasi dan presisi yang masih dapat diterima sebesar 11,06 $\mu \mathrm{g} / \mathrm{mL}$. Dengan diketahui batas kuantitasi dapat memberikan pedoman berapa konsentrasi asam klorogenat terendah dalam ekstrak etanol 95\% daun Yakon yang dapat dipersiapkan untuk penetapan kadar.

\section{Hasil Penetapan Kadar Asam Klorogenat dalam Ekstrak Etanol 95\% Daun Yakon}

Kadar rata-rata asam klorogenat dalam ekstrak daun Yakon 1,02\% dengan simpangan baku relatif (SBR) 1,13\%. Hasil penetapan kadar disajikan pada Tabel 1.

Tabel 1. Hasil penetapan kadar asam klorogenat dalam ekstrak etanol 95\%

\begin{tabular}{cccccc}
\hline $\begin{array}{l}\text { Bobot Ekstrak } \\
(\mathbf{m g})\end{array}$ & $\begin{array}{l}\text { Konsentrasi } \\
\text { Larutan } \\
(\mathbf{m g} / \mathbf{m L})\end{array}$ & $\begin{array}{c}\text { Luas } \\
\text { Puncak } \\
\text { Baku } \\
\text { Larutan Uji }\end{array}$ & $\begin{array}{c}\text { Konsentrasi } \\
\text { Baku } \\
\text { Pembanding } \\
(\mathbf{m g} / \mathbf{m L})\end{array}$ & $\begin{array}{c}\text { Luas } \\
\text { Puncak } \\
\text { Baku } \\
\text { Pembanding }\end{array}$ & $\begin{array}{c}\text { Kadar asam } \\
\text { klorogenat }\end{array}$ \\
\hline 50,78 & 1,016 & 258634 & & & 1,03 \\
50,54 & 1,011 & 254166 & 0,180 & 247098 & 1,01 \\
50,37 & 1,017 & 256127 & & & 1,03 \\
\hline
\end{tabular}




\section{Hasil Uji Akurasi dan Uji Presisi}

Uji perolehan kembali dilakukan untuk mengetahui akurasi dari metode analisis dengan menghitung persen perolehan kembali larutan baku yang ditambahkan ke dalam sampel. Uji akurasi dilakukan dengan standard addition method. Uji presisi dilakukan untuk mengetahui besarnya ketelitian atau kedekatan hasil tiap pengerjaan terhadap pengukuran sampel dengan konsentrasi yang sama secara berulang dengan cara perhitungan simpangan baku dan koefisien variasi (simpangan baku relatif). Hasil uji akurasi dan presisi dapat dilihat pada Tabel 2. Hasil penetapan perolehan kembali didapatkan hasil rata-rata 97,50\%. Menurut pustaka, persen akurasi yang diperbolehkan berdasarkan kadar analit pada penetapan kadar, yaitu dengan jumlah analit $\geq 1 \%$ adalah $97-103 \%$ (Harmita, 2012).

Tabel 2. Hasil Uji Akurasi dan Presisi Ekstrak Daun Yakon Etanol 95\%

\begin{tabular}{|c|c|c|c|c|c|c|}
\hline \multirow{2}{*}{$\begin{array}{l}\text { Konsentrasi Baku } \\
\text { Pembanding yang } \\
\text { Ditambahkan } \\
(\mu \mathrm{g} / \mathrm{mL})\end{array}$} & \multirow{2}{*}{$\begin{array}{c}\text { Luas } \\
\text { Puncak } \\
\text { Larutan } \\
\text { Uji }\end{array}$} & \multirow{2}{*}{$\begin{array}{c}\text { Konsentrasi } \\
\text { Baku } \\
\text { Pembanding } \\
(\mu \mathrm{g} / \mathrm{mL})\end{array}$} & \multirow{2}{*}{$\begin{array}{c}\text { Luas } \\
\text { Puncak Baku } \\
\text { Pembanding }\end{array}$} & \multirow{2}{*}{$\begin{array}{l}\text { Luas } \\
\text { Puncak } \\
\text { Sampel }\end{array}$} & \multicolumn{2}{|c|}{ Perolehan Kembali } \\
\hline & & & & & $(\%)$ & $(\%)$ \\
\hline 3,7346 & 174,261 & & & & 98,38 & \\
\hline 3,7102 & 173,774 & 3,7726 & 75.365 & & 98,35 & \\
\hline 3,6755 & 173,081 & & & & 97,43 & \\
\hline 7,2759 & 274,650 & & & & 96,43 & $\begin{array}{c}\text { Rata-rata } \\
=97,50 \\
\text { SR }-\end{array}$ \\
\hline 7,3027 & 275,295 & 7,5453 & 181.473 & 99.656 & 96,79 & $\begin{array}{c}\mathrm{SB}= \\
0,7703 \\
\mathrm{SBR}-\end{array}$ \\
\hline 7,2774 & 274,684 & & & & 96,48 & $\begin{array}{l}\text { SBR }= \\
0,7901\end{array}$ \\
\hline 11,0784 & 432,674 & & & & 97,88 & \\
\hline 11,0490 & 431,792 & 11,3179 & 340.218 & & 97,62 & \\
\hline 11,1058 & 433,498 & & & & 98,13 & \\
\hline
\end{tabular}

Pada uji presisi diperoleh simpangan baku relatif (SBR) sebesar 0,79\%. Persyaratan simpangan baku relatif untuk uji presisi yaitu $\leq 2 \%$, sehingga hasil uji presisi yang dilakukan memenuhi persyaratan. Hasil ini menunjukkan bahwa tidak ada perbedaan nyata antara bobot baku pembanding yang ditambahkan dengan bobot baku pembanding yang diperoleh kembali. 


\section{KESIMPULAN}

Kondisi optimum sistem KCKT fase balik untuk penetapan kadar asam klorogenat dalam ekstrak etanol 95\% daun yakon yaitu sistem fase balik dengan fase diam XBridge $\mathrm{C} 18$, fase gerak asam format $0,1 \%$ dalam air-asam format $0,1 \%$ dalam asetonitril dengan elusi gadien, laju alir $0,8 \mathrm{~mL} / \mathrm{menit}$, dan detektor UV $328 \mathrm{~nm}$. Hasil pengujian diperoleh batas deteksi 3,32 $\mu \mathrm{g} / \mathrm{mL}$, batas kuantitasi 11,06 $\mu \mathrm{g} / \mathrm{mL}$, SBR $0.79 \%$ dan uji perolehan kembali $97.50 \%$. Kadar asam klorogenat dalam ekstrak daun yakon diperoleh sebesar $1,02 \%$.

\section{UCAPAN TERIMA KASIH}

Penulis mengucapkan terima kasih pada Jatmiko Andrawino atas bantuannya dalam penyiapan ekstrak dan Fakultas Farmasi Universitas Pancasila atas dana penelitian yang diberikan melalui Penelitian Insentif Fakultas Farmasi Nomor: 006/FF$\mathrm{UP} / \mathrm{NPJ} / \mathrm{PPI} / \mathrm{V} / 2017$.

\section{DAFTAR PUSTAKA}

Ayelign, A. and Sabally, K., 2013. Determination of Chlorogenic Acids (CGA) in Coffee Beans Using HPLC. American Journal of Research Communication 1(2), 78-91.

Baroni, S., Suzuki-Kemmelmeier, F., Caparroz-Assef, S. M., Cuman, R. K. N., and Bersani-Amado, C. A., 2008. Effect of Crude Extracts of Leaves of Smallanthus Sonchifolius (Yacon) on Glycemia in Diabetic Rats. Revista Brasileira de Ciências Farmacêuticas 44(3), 521-530. doi: 10.1590/S1516-93322008000300024.

Baroni, S., da Rocha, B. A., de Melo, J. O., Comar, J. F., Caparroz-Assef, S. M., and Bersani-Amado, C. A., 2016. Hydroethanolic Extract of Smallanthus Sonchifolius Leaves Improves Hyperglycemia of Streptozotocin Induced Neonatal Diabetic Rats. Asian Pacific journal of tropical medicine 9(5), 432-436. doi: 10.1016/j.apjtm.2016.03.033.

de Andrade, E. F., de Souza Leone, R., Ellendersen, L. N., and Masson, M. L., 2014. Phenolic Profile and Antioxidant Activity of Extracts of Leaves and Flowers of Yacon (Smallanthus sonchifolius). Industrial Crops and Products 62, 499-506. doi: 10.1016/j.indcrop.2014.09.025.

Grau, A., 1997. Yacon. Smallanthus sonchifolius (Poepp. And Endl.) H. Robinson. Andean roots and tubers: Ahipa, arracacha, maca and yacón, 199-242.

Harmita, H., 2012. Petunjuk Pelaksanaan Validasi Metode dan Cara Perhitungannya. Pharmaceutical Sciences and Research (PSR) 1(3), 117-135. doi: 10.7454/psr.v1i3.3375.

Zeng, Z., Ji, Z., Hu, N., Chen, S., Bai, B., Wang, H., and Suo, Y., 2017. Synchronous 
Determination with Double-Wavelength by RP-HPLC-UV and Optimization of Ultrasound-Assisted Extraction of Phenolic Acids from Caragana Species Using Response Surface Methodology. Journal of pharmaceutical and biomedical analysis 140, 182-189. doi: 10.1016/j.jpba.2017.03.017. 